\begin{tabular}{cc} 
MANAGEMENT ISSUES IN & INDUSTRIAL \\
HEALTHCARE SYSTEM & MANAGEMENT \\
\hline
\end{tabular}

\title{
An overview of the social functions of gossip in the hospitals
}

\author{
Maryam Babaei Aghbolagh, Farzad Sattari Ardabili*
}

Department of Executive Management, Science and Research Branch, Islamic Azad University, Ardabil, Iran

\begin{tabular}{ll}
\hline & ABSTRACT \\
\cline { 2 - 2 } $\begin{array}{l}\text { Keywords: } \\
\text { Gossip, Functions of }\end{array}$ & $\begin{array}{l}\text { This article deals with the functions of gossip in society and institutional environments. } \\
\text { Gossip, Organization, } \\
\text { Stress, Organizational }\end{array}$ \\
Interests & $\begin{array}{l}\text { According to available literature, the functions of gossip in society can be divided in to four } \\
\text { Among organizational employees such as hospital nurses, gossiping has positive and } \\
\text { negative results at both the individual and organizational levels. Thus, nurses can reduce } \\
\text { Correspondence: }\end{array}$ \\
Sattari.farzad@gmail.com & Meanwhile, uncontrolled or negative gossip can be harmful for organizational interests.
\end{tabular}

(C)AIMI Journals

\section{Introduction}

Gossip is an integral part of the social environments which can be one of the most influential factors in people's organizational relations in of terms organizational behavior. Speaking about newcomers into the organization (Mills, 2010), their character and appearance (Nevo, Nevo, \& Derech-Zehavi, 1993), new management decisions, the possibility of layoffs by the new manager (Grosser, Lopez-Kidwell, \& Labianca, 2010), etc. Therefore, gossips are considered as a part of people's daily organizational lives because people increasingly tend to share such kind of information during their interpersonal communication processes. According to the evidence, more than two-third of people's time is dedicated to talking about others in their absence (Hartung \& Renner, 2013).

Gossip as social phenomenon has been studied in various disciplines of the humanities (Fine \& Rosnow, 1978; Houmanfar \& Johnson, 2004). The common aspects of these disciplines consist of occurring in informal communication networks, happening between two 
or more persons, not being present the target of the gossip during gossip episode, and arising from evaluation.

Given that the gossip is considered as a manifestation of the organizational culture, it reflects valuable insights of the quality and working climate of the organizational work; therefore, an in-depth investigation of gossip has become necessary in enterprise networks by researchers of organizational behavior as a part of the social environment (Wittek \& Wielers, 1998). Studies show that gossips have some positive and negative effects on the organizations. Some of those including negative gossips can cause employee's poor morale and can destroy the productivity of the organizational objectives, but in some circumstances gossips can play a positive role in the organization and help management to promote effective decision making and also to get a better understanding of the organizational atmosphere. The purpose of this review paper is to study the tendency of people to spread the gossips and the role plays the gossips within hospital among nursing staff with direct and various connections.

\section{The Review of Literature}

Table 1 presents different definitions of gossip according to different authors.

Table 1

Different Definitions of Gossip

\begin{tabular}{|c|c|}
\hline Resources & Definition \\
\hline Nevo et al. (1993) & Talking (written or spoken) in the case of someone who is absent \\
\hline DiFonzo and Bordia (2007) & Community evaluative discussions which are stated about other people. \\
\hline Van Iterson and Clegg (2009) & $\begin{array}{l}\text { Informal evaluative conversation between two or more people in the organization about a member of } \\
\text { the organization who is absent }\end{array}$ \\
\hline Lee and Workman (2013) & Gossip is evaluative informal discussion about the social environment member who is absent. \\
\hline
\end{tabular}

Social functions of gossip are recognized differently among different people in various social situations. According to psychologists, people enter the process of gossiping for building more intimacy with others, obtaining information, and reaching power and entertainment. People have a tendency to spread gossip though sharing values and compare their life experiences, feelings, and beliefs with others. According to sterling (1956), gossip is an important societal phenomenon that facilitates the flow of information, and improves entertainment, and control cohesion in groups. The literature review provides some information about many functions of gossip and among them only four main social functions are common including information, entertainment, friendship, and penetration. Table 2 summarizes the functions and performance indicators of Gossip from different authors' perspectives. 
Table 2

The Functions and Performance Indicators of Gossip

\begin{tabular}{llc}
\hline Resources & Performance Indicators of Gossip & Gossip Functions \\
\hline $\begin{array}{l}\text { Grosser, Lopez, } \\
\text { Kidwell, and } \\
\text { Labianca (2010) }\end{array}$ & $\begin{array}{l}\text { By collecting information through gossip, people are constantly evaluating and compare } \\
\text { themselves with others. } \\
\text { Gossip is a means by which persons compare themselves with others and the motivation } \\
\text { is the need to improve themselves. }\end{array}$ & Information \\
$\begin{array}{l}\text { DiFonzo and Bordia } \\
\text { (2007) }\end{array}$ & Gossip reduces social isolation through creating sense of belonging & Entertainment \\
\hline $\begin{array}{l}\text { Taylor (2005) } \\
\begin{array}{l}\text { Nevo, Nevo, and } \\
\text { Derech-Zehavi } \\
\text { (1993) }\end{array}\end{array}$ & $\begin{array}{l}\text { Gossip cause friendship among persons and a distinction between the self and others. } \\
\text { ranking officials }\end{array}$ & Friendship \\
$\begin{array}{l}\text { Noon and Delbridge } \\
\text { (1993) }\end{array}$ & $\begin{array}{l}\text { Penetration is a function of gossip by which people attempt to gather information and } \\
\text { influence others to exploit it to their advantage }\end{array}$ & Penetration \\
\hline
\end{tabular}

\section{Information}

Gossip has been defined as an information exchange mechanism and an efficient tool to foster cultural learning. At group level, people need to have access to some information which is difficult to be obtained through direct communication to compare themselves with other members of the group (Michelson \& Mouly, 2002; Wert \& Salovey, 2004). Therefore, people obtain their required information through gossiping and escaping from making any kind of direct contact (Foster, 2004). The researchers believe that the unequal distribution of information improves data transfer through gossiping and makes it worthwhile. Protecting the confidentiality of news sources and informality of interaction and dialogue between individuals are two essential conditions for transferring gossips among persons (Parker \& O'Reilly, 2012). The information is only given to those people who are trustworthy who keep the source of information secret (Ellwardt, Labianca, \& Wittek, 2012). One of the other conditions of information transferring via gossips is the importance of the issues (Gholipour, Fakheri Kozekanan, \& Zehtabi, 2011). Sometimes, people have extraordinary tendency to get and share their colleagues' personal information and therefore the importance of exchanged information leads to spread of gossips among people (Pezzo \& Beckstead, 2006). Informational function of gossips has been mentioned as a source of information for issues such as promotion, dismissal or other events occur for colleagues in an enterprise environment. Behavioral analysis of gossip functions is due to remove environmental ambiguities (Houmanfar \& Johnson, 2004). Researchers stated that dominance of vague laws in organizations and not having access to sufficient detailed information result in an overall increase in the amount of gossips (Mills, 2010).

\section{Entertainment}

Beersma and Van Kleef (2012) argued that gossips make people enjoy from their interactions and stated entertainment as the second function of gossip. People use gossip as an entertainment tool without emphasis on convincing others and giving too much importance to the existing environmental conditions (Noon \& Delbridge, 1993). When a gossip enters into the social network, the initial thing that comes to people's mind is that talking about the 
mentioned subject is entertaining and makes good time. In fact, talking and laughing about the strange behavior of others and stunting of others entertain people and are enjoyable for them (DiFonzo \& Bordia, 2007).

\section{Friendship}

The third social function of gossip is friendship. Gossip exchange improves peoples' understanding each other and strengthens the relationship among them; therefore, in terms of organizational behavior interact with each other in the form informal groups of friends (Houmanfar \& Johnson, 2004). People communicate with each other on the basis of their views, norms, and culture. In the early stages of friendship, people begin sharing gossips especially positive ones with minimum acceptable confidence therefore they measure indirectly the persons' trustworthiness, form friendship groups, and create social boundaries between themselves and their surroundings if the process continues and confidence increases (DiFonzo \& Bordia, 2007; Taylor, 2005). According to Dunbar (2004), gossip is considered as a means that creates social groups and provides opportunity for people to learn new things and to be known as new groups.

\section{Penetration}

Penetration is the fourth social function of gossip which refers to the control of other people's actions, thoughts, and intentions (Taylor, 2005). In the analysis of significant behaviors, verbal behavior of speakers affect on the listeners' performances. In other word, statements or gossips play a practical role in penetration (Houmanfar \& Johnson, 2004). The effects of gossips on people's behavior control their behavior and guide the behavior of individuals to gossip (Rook, Tazelaar, \& Snijders, 2011). Generally, the control of people’s behavior can influence the group and organizational behavior in a way that preserves the groups' norms and builds group cohesion (Kniffin \& Wilson, 2005). People whose behavior are beyond the organizational or group norms are the target of malicious gossips such as negative ones (Ellwardt, Labianca, \& Wittek, 2010). In gossip-based communication, the gossips are considered as the normal punishment for the people who violate the norms which cause to their behavioral modification or excluding from the group. In fact, gossip as a mechanism thwarts individual behaviors of who acts in accordance with her/his individual desires and guide the behavior of group members towards achieving the specified organizational goals (McAndrew, Bell, \& Garcia, 2007). At individual-level, despite the positive function of group-level gossip, people may use gossips to gain admiration and fame and thereby can penetrate among others (Nevo et al., 1993). Kniffin and Wilson (2005) stated that negative gossips can negatively affect on the competitors' popularity and fame in society.

\section{Functions of Gossip in the Organization}

In an organizational setting, employees participate in the process of gossiping to deal with organization's internal policies which cause stress and anxiety such as personnel changes, methods, etc., through forming informal groups of friends (Ybema, 2004). In this situation, people reach to the common sense when they talk about the gossips in order to reduce their 
stress, depression, and anxiety (Pezzo \& Beckstead, 2006). In fact, it can be assumed that gossip is an important component of informal group formation.

Nursing groups as organizational groups work in the stressful working environments; therefore, nursing working environment is considered as one of difficult and challenging work environments. In addition to difficulties finding in nursing job, they may observe the patients' physical conditions and problems and experience some emotional conflicts (Waddington, 2005). In addition to high levels of work stress and workload among nurses, emotional conflicts may make them more vulnerable. Teamwork and social interaction among nurses provide a supportive environment for the formation of informal groups to act as a defense mechanism against workplace stress and emotional conflicts (Thomas \& Rozell, 2007). In fact, nurses with high level of social interactions are in the best positions to produce and disseminate gossip. Changing the topics of conversations from work issues to personal subjects, detach their minds from routine patterns and stressful work conditions of hospital and patients and help them to stay calm and jolly (Georganta, Panagopoulou, \& Montgomery, 2014).

Despite the positive effects of gossips which reduce the level of stress among employees', unmanaged gossips have also some negative effects on the nurses in the absence of gossip management; therefore, both positive and negative effects can be existed (Rosnow \& Foster, 2005). Thomas and Rozell (2007) argued that unmanaged gossips can have negative effects on the nursing environment and damage their relationship and reputation. Moreover, the results of Georganta, Panagopoulou, and Montgomery's study (2014) revealed that there is a positive correlation between negative gossips and nurses' and doctors' emotional exhaustion, depersonalization, and suboptimal care while there is a negative correlation between patient safety culture and job commitment. Meanwhile, Waddington (2005) indicated that the gossip is an important aspect of nurses' job descriptions by which they express their feelings towards their patients and colleagues. In fact, nurses express a wide range of their negative emotions about others including anger, annoyance, anxiety and etc. through gossip and as a result they gain emotional results such as support and confidence (Waddington \& Michelson, 2007).

\section{Discussion and Conclusion}

The purpose of this study was to review the social functions of gossip especially in the hospitals among nurses. Hospital management is more difficult for managers compared to other organizations due to the presence of relatively large number of employees and multiple specialized posts. Special working conditions, teamwork necessity, and also direct communication with patients are contributing factors in increasing interaction among hospitals' employees and forming informal groups of friends. Gossips play a fundamental role in the formation of these groups.

Nurses, in their friendly gatherings, express their feelings and concerns about their working environment and other different issues through participating in environmental gossips which may have positive and negative consequences at both individual and organization level. Despite the potentially positive consequences of gossips at the individual 
level, it is possible that unmanaged gossips especially negative gossips cause problems at any organizational level. For this purpose, the researchers acknowledge that managers should not attempt to eliminate gossips from organizational environments due to their positive results (Mills, 2010).

Therefore, managers can make effective and timely decisions about their organizations' internal policies and guidelines through focusing their attention on the internal mechanisms of organizational environment and obtaining timely, accurate, and relevant information about organizational situations (Feldman \& March, 1981). These managers can control and manage the spread of the gossips at the organizational level through applying some management strategies. Timely enterprises of managers and their awareness of the content of current gossips can help them to prevent the negative consequences of gossips.

\section{References}

Beersma, B., \& Van Kleef, G. A. (2012). Why people gossip: An empirical analysis of social motives, antecedents, and consequences. Journal of Applied Social Psychology, 42(11), 2640-2670.

DiFonzo, N., \& Bordia, P. (2007). Rumor, gossip, and urban legends. Diogenes, 54(1), 19-35.

Dunbar, R. I. M. (2004). Gossip in evolutionary perspective. Review of General Psychology, 8(2), 100-110.

Ellwardt, L., Labianca, G. J., \& Wittek, R. (2012). Who are the objects of positive and negative gossip at work? A social network perspective on workplace gossip. Social Networks, 34(2), 193-205.

Feldman, M. S., \& March, J. G. (1981). Information in organizations as signal and symbol. Administrative Science Quarterly, 26(2), 171-186.

Fine, G. A., \& Rosnow, R. L. (1978). Gossip, gossipers, gossiping. Personality \& Social Psychology Bulletin, 4(1), 161-168.

Foster, E. K. (2004). Research on gossip: Taxonomy, methods, and future directions. Review of General Psychology, 8(2), 78-99.

Georganta, K., Panagopoulou, E., \& Montgomery, A. (2014). Talking behind their backs: Negative gossip and burnout in hospitals. Burnout Research, 1(2), 76-81.

Gholipour, A., Fakheri Kozekanan, S., \& Zehtabi, M. (2011). Utilizing gossip as a strategy to construct organizational reality. Business Strategy Series, 12(2), 56-62.

Grosser, T. J., Lopez-Kidwell, V., \& Labianca, G. (2010). A social network analysis of positive and negative gossip in organizational life. Group \& Organization Management, 35(2), 177-212.

Hartung, F. M., \& Renner, B. (2013). Social curiosity and gossip: Related but different drives of social functioning. PLoS One, 8(7), 1-9.

Houmanfar, R., \& Johnson, R. (2004). Organizational implications of gossip and rumor. Journal of Organizational Behavior Management, 23(2/3), 117-138.

Kniffin, K. M., \& Wilson, D. S. (2005). Utilities of gossip across organizational levels. Human Nature, 16(3), $278-292$.

Lee, S. H., \& Workman, J. E. (2013). Gossip, self-monitoring, and fashion consumer groups. Clothing \&Textiles Research Journal, 31(2), 67-80.

McAndrew, F. T., Bell, E. K., \& Garcia, C. M. (2007). Who do we tell and whom do we tell on? Gossip as a strategy for status enhancement. Journal of Applied Social Psychology, 37(7), 1562-1577.

Michelson, G., \& Mouly, V. S. (2002). You didn't hear it from us but...towards an understanding of rumor and gossip in organisations. Australian Journal of Management, 27(s1), 57-65.

Mills, C. (2010). Experiencing gossip: The foundations for a theory of embedded organizational gossip. Group \& Organization Management, 35(2), 213-240.

Nevo, O., Nevo, B., \& Derech-Zehavi, A. (1993). The development of the tendency to gossip questionnaire: Construct and concurrent validation for a sample of Israeli college students. Educational \& Psychological Measurement, 53(4), 973-981.

Noon, M., \& Delbridge, R. (1993). News from behind my hand: Gossip in organizations. Organization Studies, 14(1), 2336. 
Parker, N., \& O’Reilly, M. (2012). Gossiping as a social action in family therapy: The pseudo-absence and pseudo-presence of children. Discourse Studies, 14(4), 457-475.

Pezzo, M. V., \& Beckstead, J. W. (2006). A multilevel analysis of rumor transmission: Effects of anxiety and belief in two field experiments. Basic \& Applied Social Psychology, 28(1), 91-100.

Rook, G., Tazelaar, F., \& Snijders, C. (2011). Gossip and reputation in business networks. European Sociological Review, 27(1), 90-106.

Rosnow, R. L., \& Foster, E. K. (2005). Rumor and gossip research. Psychological Science Agenda, 19(4), 1-4.

Sterling, R. B. (1956). Some psychological mechanisms operative in gossip. Social Forces, 34, 262-267.

Taylor, E. M. (2005). Gossip as an interpersonal communication phenomenon (Unpublished doctoral dissertation). West Virginia University,_Morgantown.

Thomas, S. A., \& Rozell, E. J. (2007). Gossip and nurses: Malady or remedy? The Health Care Manager, 26(2), 111-115.

Van Iterson, A., \& Clegg, S. R. (2008). The politics of gossip and denial in inter-organizational relations. Human Relations, 61(8), 1117-1137.

Waddington, K. (2005). Behind closed doors: The role of gossip in the emotional labor of nursing work. International Journal of Work Organization \& Emotion, 1(1), 35-47.

Waddington, K., \& Michelson, G. (2007). Analysing gossip to reveal and understand power relationships, political action, and reaction to change inside organisations. Paper presented at the Talk, Power, and Organization Change at CMS conference, Manchester.

Wert, S. R., \& Salovey, P. (2004). A social comparison account of gossip. Review of General Psychology, 8(2), 122-137.

Wittek, R., \& Wielers, R. (1998). Gossip in organizations. Computational \& Mathematical Organization Theory, 4(2), 189204.

Ybema, S. (2004). Managerial postalgia: Projecting a golden future. Journal of Managerial Psychology, 19(8), 825-841. 